\title{
Pharmacogenetics of Major Depressive Disorder: Progress in Two Serotonergic Targets
}

\author{
Chidiebere Michael Iro ${ }^{1}$, Rami Hamati ${ }^{1}$ \\ ${ }^{1}$ University of Ottawa, Faculty of Science, Ontario, Canada
}

ABSTRACT

\begin{abstract}
Major depressive disorder (MDD) is a multifaceted, debilitating condition affecting over 300 million people worldwide. It contributes significantly to social, psychological and economic burdens on individuals and on society at large. Currently, the most widely prescribed antidepressant medications are selective serotonin reuptake inhibitors (SSRIs), which act by blocking serotonin (5-HT) reuptake into presynaptic neurons, thereby increasing the extracellular 5-HT concentration in the brain. However, response to SSRIs and other psychotropic medications used to treat depression is highly variable, with only about one third of patients responding to treatment with an SSRI. This may reflect, at least in part, the genetic heterogeneity of depressed individuals. Studies investigating the genetic components of depression aim to improve treatment outcomes and possibly pave the way for personalized medicine in which the first medication prescribed is the one most likely to result in remission. This review presents the results of several studies on two 5-HT related genes: SLC6A4 and HTR2A, which encode for the serotonin transporter and the serotonin-2A receptor, respectively. Extensive studies have demonstrated that possessing two copies of the long allele (L/L) of the SLC6A4 gene can predict better responses to the SSRI Escitalopram. However, this finding was significant only in the Caucasian population. In addition to this, several single nucleotide polymorphisms in the HTR2A gene also predict clinical outcome, although molecular mechanisms remain unclear. Hence, the results indicate that while there is significant potential for predicting treatment response associated with these and other genetic targets, there is much work left to be done to establish conclusive evidence for and feasibility of pharmacogenetic testing.
\end{abstract}

\section{RÉSUMÉ}

La dépression majeure est une condition variée et débilitante qui affecte plus de 300 millions-personne mondialement. Elle contribue de façon significative à des fardeaux sociaux, psychologiques et économiques sur les individus ainsi que sur la société en général. Actuellement, les médicaments antidépresseurs les plus prescrits sont les inhibiteurs sélectifs de la recapture de la sérotonine (ISRS), qui agissent en bloquant la recapture de la sérotonine (5-HT) aux neurones présynaptiques, afin d'augmenter la concentration extracellulaire de la 5-HT dans le cerveau. Cependant, la réponse aux ISRS et aux autres médicaments psychotropes utilisés pour traiter la dépression est très variable, avec seulement un tiers des patients qui répondent à un traitement de IRSR. C'est un reflet, en part, de l'hétérogénéité des individus déprimés. Les études examinant les composants génétiques de la dépression visent à améliorer les résultats des traitements et à ouvrir la voie si possible à la médecine personnalisée, dans laquelle le premier médicament prescrit est le plus probable à causer la rémission. Cette revue présente les résultats de plusieurs études sur deux gènes reliés à la $5-\mathrm{HT}$ : SLC6A4 et HTR2A, qui encodent le transporteur de la sérotonine et le récepteur sérotoninergique-2A respectivement. Des études extensives ont démontré que la possession de deux copies de l'allèle long (L/L) du gène SLC6A4 peut prédire de meilleures réponses à l'IRSR Escitalopram. Toutefois, ce résultat n'a été pertinent qu'avec la population caucasienne. En plus, plusieurs polymorphismes d'un seul nucléotide dans le gène HTR2A prédisent également le résultat clinique, bien que les mécanismes moléculaires restent incertains. Ainsi les résultats indiquent que même s'il y a beaucoup de potentiel pour prédire les réponses aux traitements associés avec ces derniers et d'autres traitements génétiques, il reste encore beaucoup du travail à faire afin d'établir l'évidence conclusive et la faisabilité de l'analyse pharmacogénétique.

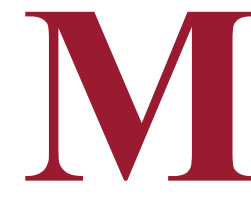

ajor depressive disorder (MDD) is a multifaceted, debilitating condition affecting over 300 million people worldwide (1). It often contributes significantly to social,

psychological and economic burdens on individuals and society at large (2). Furthermore, the World Health Organization (WHO) has declared MDD to be the leading cause of disability worldwide (1). According to the Diagnostic and Statistical

Keywords: Pharmacogenetics; 5-HT2AR; SLC6A4; SSRIs; MDD 
Manual of Mental Disorders, Fifth Edition (DSM-5), depression is characterized by the presence of at least five out of nine symptoms for a minimum of two weeks (3). Some of these symptoms may appear ambiguous and include fluctuations in weight, sleep and energy; however, there must be the presence of a depressed mood and/or anhedonia (loss of pleasure in formerly pleasurable activities), which are unexplainable by bereavement, drug use or other mental disorders for a diagnosis of MDD. Investigations into the etiology of MDD have unveiled several environmental risk factors such as childhood abuse, childhood neglect and stressful life events (4). The contributions of genetic risk factors to MDD are also significant, as estimates of inheritance based on twin studies suggest a heritability of $40-50 \%$ (4-10).

It is likely that genetic factors may mediate responses to psychotropic medications, giving rise to pharmacogenetics, defined as the study of the genetic variants associated with producing a drug response (11). Variance in the human genome arises from several genetic alterations including deletions, insertions and changes in the number of copies of base pairs. However, the most common and most studied variations are those that arise from single-nucleotide polymorphisms (SNPs) in candidate genes (12). SNPs are substitution mutations at a given location on a chromosome (11) that may alter the function of the encoded protein. Most pharmacogenetic studies in depression have focused on identifying SNPs in loci that encode proteins related to neurotransmission.

Currently, the most widely prescribed antidepressant medications are selective serotonin reuptake inhibitors (SSRIs), which act by blocking serotonin (5-HT) reuptake into presynaptic neurons, thereby increasing the extracellular 5-HT concentration in the brain. Response to SSRIs and other psychotropic medications used to treat depression is highly variable, with only about one third of patients responding to treatment with an SSRI (13). This may reflect, at least in part, the genetic heterogeneity of depressed individuals (12). Irrespective of the variability in response, SSRIs are considered first-line drugs in the treatment of MDD (14). Hence, this review will focus on two well-studied 5-HT related genes: SLC6A4 and HTR2A. To date, several studies have provided a comprehensive overview of the genes involved in predicting an antidepressant response $(12,15)$. In contrast, few studies have addressed how these genetic alterations may alter key molecular processes that are correlated with producing a therapeutic effect, and ultimately affect the prescriber's choice of medication (often referred to as personalized medicine). Furthermore, the review will address what types of studies are required to further the field of pharmacogenetics.

\section{ARTICLE SELECTION CRITERIA}

Research articles were selected by conducting a search for key words on "google scholar" and "PubMed" websites. Key words include: pharmacogenetics, major depressive disorder, SLC6A4, HTR2A, antidepressant response, serotonin transporter and serotonin-2A receptor. Peer-reviewed articles observing the effect of genetic alterations on the antidepressant response and/or treatment outcome were included. Furthermore, the antidepressant response and/or treatment outcome refers to the primary outcome measure; commonly reported as the difference between baseline and last-assessment scores calculated by the Hamilton Rating Scale for Depression (HRSD) or the Montgomery and Asberg Rating Scale (MADRS). All positive and/or negative results on the antidepressant response, as well as sample size, were reported.

\section{RESULTS}

SLC6A4 - candidate gene encoding the serotonin re-uptake transporter (5-HT transporter)

The 5-HT transporter has been the target of numerous studies since the discovery of SSRIs, which bind to and inhibit the 5-HT transporter to produce a therapeutic effect. Counterintuitively, mice lacking the 5-HT transporter demonstrate an increase in anxiety-like and depressive-like behaviours (16). Nevertheless, preclinical studies have demonstrated the importance of the 5-HT transporter in mediating depressive behaviours. Indeed, SLC6A4 is perhaps the most studied gene with a potential for predicting an antidepressant response $(17,18)$. In particular, the 5-HTTLPR (5-HT transporter linked polymorphic region) in the SLC6A4 gene has been widely researched. There are two alleles in the 5-HTTLPR (L; long allele, or S; short allele), which can combine for three possible genotypic variations: $\mathrm{L} / \mathrm{L}, \mathrm{L} / \mathrm{S}$, and S/S (19). A meta-analysis of 15 studies from 1435 subjects sought to determine the effect of the 5-HTTLPR on the antidepressant response. Their results showed a significant correlation between the L allele of the 5-HTTLPR and clinical response in patients undergoing treatment with SSRIs such as citalopram, fluoxetine, sertraline and paroxetine (20). The effect of the 5-HTTLPR was most pronounced for response within 4 weeks of treatment in Caucasian patients receiving these medications (20). Furthermore, patients homozygous for the $L / L$ allele showed a better response to these SSRIs than homozygous S/S or heterozygous (L/S) patients. More 
recently, a meta-analysis by Porcelli et al (2012) of 33 studies from 5479 subjects confirmed that individuals carrying the $\mathrm{L} / \mathrm{L}$ genotype were about one and a half times more likely to remit on SSRIs (21). Closer analysis revealed that only $L$ carriers of Caucasian ethnicity predicted antidepressant response and remission (21). However, despite the successful identification of a genetic predictor, several studies failed to find any effect of the 5-HTTLPR on antidepressant response (22-24). Negative results could be due to several reasons such as strict inclusion criteria and failing to analyze results based on the class of antidepressant medication (21).

Epigenetic alterations can also influence the antidepressant response, specifically the methylation of the promoter region of SLC6A4 encoded by 5-HTTLPR. A study by Zhao et al. (2013) involving 84 matched monozygotic twins found that variations in methylation levels of the promoter region of the $5-\mathrm{HT}$ transporter gene were associated with variation in depressive symptoms (25). On average, a 10\% increase in the methylation of the $5-\mathrm{HT}$ transporter was associated with a $4.4 \mathrm{x}$ increase in the patient's Beck Depressive Inventory II (BDI-II) score, which suggests an increase in depressive symptom severity. In contrast to this, Domschke et al (2014) found that a lower average 5-HT transporter methylation across all nine DNA sites investigated in the 5-HTTLPR was associated with an impaired response to escitalopram after six weeks of treatment (26). As both rodent and human studies suggest that the $5-\mathrm{HT}$ transporter is an important marker for pharmacogenetics, further research to understand if/how it can be targeted to improve treatment response in patients with MDD is warranted.

HTR2A - candidate gene encoding the serotonin-2A receptor (5-HT2AR)

Pre-clinical studies have suggested a role for the 5-HT2AR in depression onset as well as treatment outcome. For instance, in 5-HT2AR KO mice, corticosterone administration increased depressive-like symptom severity relative to wildtype controls (27). These mice also failed to respond to SSRIs as assessed by the forced swim test: a measure of despair, where rodents are placed in an inescapable container filled with water and escape-related movements are monitored. In this paradigm, antidepressant response is associated with increased escape-related movement over a longer period. In addition to poor performance in the forced swim test, 5-HT2AR KO mice did not show an SSRI-induced increase in neurogenesis; a common neurobiological effect of several antidepressants (28). Together, these studies indicate 5-HT2AR $\mathrm{KO}$ mice are resistant to antidepressant treatment, suggesting that the 5-HT2AR may prove useful in predicting treatment outcome. Human studies have also provided evidence for the involvement of the 5-HT2AR in mediating an antidepressant response. At least three studies examining post-mortem brain tissue have reported a decrease in 5-HT2AR expression in the hippocampus of individuals with MDD, while a positron emission tomography (PET) study reported no change (29-32). Furthermore, these changes were hypothesized to be due to hypersensitive 5-HT2AR (32). Additionally, in the frontal cortex of human participants, the 5-HT2A receptor has been shown to be downregulated with SSRI treatment and is correlated with the improvement of clinical symptoms (33). A study by Cutler et al also showed that medications that block the 5-HT2A receptor such as quetiapine are effective as a monotherapy in MDD (34). Furthermore, several medications used as adjuncts in MDD, namely aripiprazole, brexpiprazole and cariprazine block the 5-HT2A receptor as well (35-37). Together, these human studies demonstrate the importance of blocking the 5-HT2AR in improving clinical outcome.

Indeed, a number of studies have confirmed the predictive value of several SNPs within HTR2A. The most recent meta-analysis using pooled data from 11 studies $(n=1775)$ found that the rs6313 and rs7997012 were associated with a higher response rate to antidepressants in MDD patients (38). Although a third SNP, rs6311, was not predictive of treatment outcome (38), a meta-analysis consisting of seven studies $(n=590)$ found that it was predictive of adverse effects associated with SSRIs (39). Overall, there appear to be several SNPs within the 5-HT2AR that may predict treatment outcome.

\section{DISCUSSION}

Genetic variance produces changes in key molecular mechanisms underlying the antidepressant response. In the $S L C 6 A 4$ gene, the $\mathrm{L}$ allele is more efficient at transporting $5-\mathrm{HT}$ while the $\mathrm{S}$ allele confers reduced re-uptake of 5-HT into the presynaptic neuron (19). As the $L$ allele confers greater transporter efficacy, the administration of an SSRI may inhibit re-uptake to a greater degree relative to an individual with an $\mathrm{S}$ allele, resulting in better treatment outcome. Furthermore, mice homozygous for the transporter (analogous to L/L) exhibited a gradual recovery of 5-HT neuronal firing after 21 days of administration of the SSRI escitalopram, which was not the case in mice heterozygous at the serotonin transporter (analogous to $\mathrm{L} / \mathrm{S} ; 40$ ). This is significant because recovery of $5-\mathrm{HT}$ neuron activity has been proposed to be correlated with producing a therapeutic effect (41). Alternatively, SSRIs may not be effective in those carrying the $\mathrm{S} / \mathrm{S}$ allele because $5-\mathrm{HT}$ re-uptake is already 
impaired in these individuals. As 5-HT re-uptake is a necessary process for the recycling of neurotransmitter, inhibiting reuptake additionally may deplete 5-HT stores.

Overall, there appear to be several SNPs within HTR2A that may predict treatment outcome. Studies moving forward should assess the functional consequences of these SNPs to provide an optimized treatment regimen for individuals with depression. Functional consequences may include changes in receptor expression in the brain and altered signaling at the receptor once 5-HT is bound. For example, the rs6311 SNP has been demonstrated to possibly affect the expression of 5-HT2AR. Parsons et al. (2004) reported that the presence of rs6311 SNP (associated with a poorer antidepressant response) significantly increased promoter activity in cell-based assays (42). This implies that the 5-HT2AR is expressed to a greater extent in the brains of individuals with this receptor variant. However, others have noted that the rs6311 SNP is associated with greater methylation and consequently decreased 5-HT2AR mRNA translation efficacy in cell-based assays, implying that the 5-HT2AR is expressed to a lesser extent in the brains of individuals with this receptor variant (43). These contradictory findings highlight the need for assessing the effect of SNPs on receptor protein expression possibly through PET studies in humans. Through PET studies, one may be able to detect changes in brain receptor expression of the individuals who have inherited these SNPs. Taken together, the results suggest that while there is promise with the SLC6A4 and HTR2A genes in relation to treatment response, more studies are necessary to clarify if and how they contribute to response to antidepressant medications.

Thus far, a major limitation to research focusing on SNPs associated with depression is cost. Previous research by Perlis et al. (2009) evaluated the cost-effectiveness of pharmacogenetic testing for a single SNP (rs799012) in the HTR2A gene. The study demonstrated that pharmacogenetic testing, (i.e genetic testing to ascertain the most efficacious antidepressant medication for a specific individual), was less cost-effective than using an SSRI or bupropion as first and second-line treatments, respectively (44). In other words, it may be less expensive for clinicians to proceed with a trial-and-error approach than to test for a single pharmacogenetic marker. Although several SNPs have been identified, single gene analysis is only able to explain a small amount of the variance observed in the antidepressant response. For pharmacogenetic testing to be effective, several genes must be analyzed at once. This is now possible due to the exponential decrease in the cost of human genome sequencing and has led to the feasibility of genome-wide association studies (GWAS) (12). GWAS allow for the simultaneous analysis of hundreds of SNPs, and may reveal complex interactions between candidate genes, which could account for a larger amount of variance in the antidepressant response. For example, it has been reported that the $r 57333412$ SNP within the HTR2A gene influences the degree of 5-HT transporter expression and/or the affinity of 5-HT for the 5-HT transporter (45). Therefore, simultaneous analysis of SNPs within these two candidate genes and others may provide greater predictive value and ultimately polygenic risk scores (PRS) for a single person (12). The development of PRS may lead to improvements in predicting the antidepressant response leading to more efficient clinical care. First, it may increase the efficiency and safety of clinical trials by identifying and including those who are more likely to respond to medication and excluding those who pose a higher risk for serious adverse events (11). Secondly, pharmacogenetic testing would reduce reliance on trial-and-error prescribing and maximize the costeffectiveness of the first clinician visit (11).

\section{CONCLUSION}

In conclusion, several pharmacogenetic markers in the SLC6A4 and the HTR2A genes have been identified. Despite these robust findings, individual studies continue to find negative results. This is in part explained by the complex nature of the disease. While some environmental risk factors for depression have been identified, there seems to be no clear consensus on genetic proclivities or a clear correlation between genetic factors and drug response. To acquire more robust pharmacogenetic markers, larger sample size studies must be conducted. This is especially true for more rare SNPs within the population. Also, SNPs must be analyzed in concert to reveal interactions that may prove to be more predictive of treatment outcome. Lastly, it is imperative that we understand the functional consequences of SNPs in order to tailor antidepressant treatments to the individual. SNPs that confer greater or less signaling and/ or expression at individual receptors may be mitigated with adjunct treatment or the use of a different medication which might be more efficacious. This is a more cost-efficient future of pharmacotherapy with the potential to reduce suffering in individuals living with depression.

\footnotetext{
REFERENCES

1. World Health Organization. (2017). Depression and other common mental disorders: global health estimates.

2. Trivedi, M. H., Rush, A. J., Wisniewski, S. R., et al. Evaluation of outcomes
} 
with citalopram for depression using measurement-based care in STAR* D: implications for clinical practice. Am J Psychiatry. 2006 Jan; 163(1), 28-40.

3. American Psychiatric Association. Diagnostic and statistical manual of mental disorders: DSM-5. Washington, DC: American Psychiatric Publishing; 2013.

4. Sullivan, P. F., Neale, M. C., \& Kendler, K. S. Genetic epidemiology of major depression: review and meta-analysis. Am J Psychiatry. 2000 Oct; 157(10), 1552-1562.

5. Bierut LJ. Major Depressive Disorder in a Community-Based Twin Sample: Are There Different Genetic and Environmental Contributions for Men and Women? Arch Gen Psychiatry. 1999 Jan; 56(6):557-63.

6. Kendler KS, Neale MC, Kessler RC et al. A longitudinal twin study of personality and major depression in women. Arch Gen psychiatry. 1993 Nov; 50(11):853-62.

7. Hettema JM, Neale MC, Kendler KS. A review and meta-analysis of the genetic epidemiology of anxiety disorders. Am J Psychiatry. 2001 Oct 1;158(10):1568-78.

8. McGuffin P, Katz R, Rutherford J. Nature, nurture and depression: a twin study. Psychol Medicine. 1991 May ;21(2):329-35.

9. McGuffin $P$, Katz $R$, Watkins $S$ et al. A hospital-based twin register of the heritability of DSM-IV unipolar depression. Arch Gen Psychiatry. 1996 Feb 1;53(2):129-36.

10. Torgersen S. Genetic factors in moderately severe and mild affective disorders. Arch Gen Psychiatry. 1986 Mar 1;43(3):222-6.

11. Roses AD. Pharmacogenetics and the practice of medicine. Nature. 2000 Jun 15;405(6788):857.

12. Fabbri $C$, Serretti A. Highlights on Pharmacogenetics and Pharmacogenomics in Depression. In: Understanding Depression Vol 1. 1st ed. Singapore, Springer publishing; 2018. 3-16p.

13. Rush AJ, Trivedi MH, Wisniewski SR, et al. Acute and longer-term outcomes in depressed outpatients requiring one or several treatment steps: a STAR* D report. Focus. 2008 Jan;6(1):128-42.

14. Koenig AM, Thase ME. First-line pharmacotherapies for depression-what is the best choice. Pol Arch Med Wewn. 2009 Jul 1;119(7-8):478-86.

15. Fabbri C, Crisafulli C, Calabrò M, et al. Progress and prospects in pharmacogenetics of antidepressant drugs. Expert opin drug metab \& toxicol. 2016 Oct 2;12(10):1157-68.

16. Lira A, Zhou M, Castanon $\mathrm{N}$ et al. Altered depression-related behaviors and functional changes in the dorsal raphe nucleus of serotonin transporterdeficient mice. 2003 Jun 19;54(10):960-71

17. Malhotra AK, Murphy Jr GM, Kennedy JL. Pharmacogenetics of psychotropic drug response. Am J Psychiatry. 2004 May 1;161(5):780-96.

18. Lesch KP, Gutknecht L. Pharmacogenetics of the serotonin transporter. Prog Neuropsychopharmacol Biol Psychiatry. 2005 Jul 1;29(6):1062-73.

19. Heils A, Teufel A, Petri $S$, et al. Allelic variation of human serotonin transporter gene expression. J neurochem. 1996 Jun 1;66(6):2621-4.

20. Serretti A, Kato M, De Ronchi D, et al. Meta-analysis of serotonin transporter gene promoter polymorphism (5-HTTLPR) association with selective serotonin reuptake inhibitor efficacy in depressed patients. Mol psychiatry. 2007 Mar;12(3):247.

21. Porcelli S, Fabbri C, Serretti A. Meta-analysis of serotonin transporter gene promoter polymorphism (5-HTTLPR) association with antidepressant efficacy. Eur Neuropsychopharmacol. 2012 Apr 1;22(4):239-58.

22. Dogan O, Yuksel N, Ergun MA, et al. Serotonin transporter gene polymorphisms and sertraline response in major depression patients. Gen test. 2008 Jun 1;12(2):225-31.

23. Maron E, Tammiste A, Kallassalu K, et al. Serotonin transporter promoter region polymorphisms do not influence treatment response to escitalopram in patients with major depression. Eur neuropsychopharmacol. 2009 Jun 1;19(6):451-6.

24. Reimherr F, Amsterdam J, Dunner D, et al. Genetic polymorphisms in the treatment of depression: speculations from an augmentation study using atomoxetine. Psychiatry res. 2010 Jan 30;175(1-2):67-73.

25. Zhao J, Goldberg J, Bremner JD, et al. Association between promoter methylation of serotonin transporter gene and depressive symptoms: a monozygotic twin study. Psychosom Med. 2013 Jul;75(6).

26. Domschke K, Tidow N, Schwarte K, et al. Serotonin transporter gene hy- pomethylation predicts impaired antidepressant treatment response. Int $J$ Neuropsychopharmacol. 2014 Aug 1;17(8):1167-76.

27. Petit AC, Quesseveur G, Gressier F, et al. Converging translational evidence for the involvement of the serotonin $2 \mathrm{~A}$ receptor gene in major depressive disorder. Prog Neuro-Psychopharmacol Biol Psychiatry. 2014 Oct 3;54:76-82.

28. Qesseveur G, Petit AC, Nguyen HT, et al. Genetic dysfunction of serotonin $2 A$ receptor hampers response to antidepressant drugs: a translational approach. Neuropharmacology. 2016 Jun 1;105:142-53.

29. López-Figueroa AL, Norton CS, López-Figueroa MO et al. Serotonin 5-HT1A 5-HT1B, and 5-HT2A receptor mRNA expression in subjects with major depression, bipolar disorder, and schizophrenia. Biol psychiatry. 2004 Feb 1:55(3):225-33.

30. Mintun MA, Sheline Yl, Moerlein SM, et al. Decreased hippocampal 5-HT2A receptor binding in major depressive disorder: in vivo measurement with [18F] altanserin positron emission tomography. Biol psychiatry. 2004 Feb 1;55(3):217-24.

31. Rosel P, Arranz B, Urretavizcaya M, et al. Altered 5-HT2A and 5-HT4 postsynaptic receptors and their intracellular signalling systems IP3 and CAMP in brains from depressed violent suicide victims. Neuropsychobiology. 2004;49(4):18995.

32. Rosel P, Arranz B, San L, et al. Altered 5-HT2A binding sites and second messenger inositol trisphosphate (IP3) levels in hippocampus but not in frontal cortex from depressed suicide victims. Psychiatry Research: Neuroimaging. 2000 Oct 30;99(3):173-81.

33. Meyer JH, Kapur S, Eisfeld B, et al. The effect of paroxetine on 5-HT2A receptors in depression: an [18F] setoperone PET imaging study. Am J Psychiatry. 2001 Jan 1;158(1):78-85.

34. Cutler AJ, Montgomery SA, Feifel D, et al. Extended release quetiapine fumarate monotherapy in major depressive disorder: a placebo-and duloxetinecontrolled study. J clin psychiatry. 2009 Jul; 70(4):526-39.

35. Durgam S, Earley W, Guo H, et al. Efficacy and safety of adjunctive cariprazine in inadequate responders to antidepressants: a randomized, double-blind, placebo-controlled study in adult patients with major depressive disorder. $J$ clin psychiatry. 2016 Mar;77(3):371-8.

36. Marcus RN, McQuade RD, Carson WH, et al. The efficacy and safety of aripiprazole as adjunctive therapy in major depressive disorder: a second multicenter randomized, double-blind, placebo-controlled study. J clin psychopharmacol. 2008 Apr 1;28(2):156-65.

37. Thase ME, Youakim JM, Skuban A, et al. Efficacy and safety of adjunctive brexpiprazole $2 \mathrm{mg}$ in major depressive disorder: a phase 3, randomized, placebocontrolled study in patients with inadequate response to antidepressants. J clin psychiatry. 2015 Sep 23;76(9):1224-31.

38. Lin JY, Jiang MY, Kan ZM, et al. Influence of 5-HTR2A genetic polymorphisms on the efficacy of antidepressants in the treatment of major depressive disorder: a meta-analysis. J affect disord. 2014 Oct 15;168:430-8.

39. Kato M, Serretti A. Review and meta-analysis of antidepressant pharmacogenetic findings in major depressive disorder. Mol psychiatry. 2010 May;15(5):473.

40. Guiard BP, Mansari ME, Murphy DL, et al. Altered response to the selective serotonin reuptake inhibitor escitalopram in mice heterozygous for the serotonin transporter: an electrophysiological and neurochemical study. Int J Neuropsychopharmacol. 2012 Apr 1;15(3):349-61.

41. Blier P, De Montigny C. Current advances and trends in the treatment of depression. Trends pharmacol sci. 1994 Jul 1;15(7):220-6.

42. Parsons MJ, D'Souza UM, Arranz Mjet al. The-1438A/G polymorphism in the 5 -hydroxytryptamine type $2 \mathrm{~A}$ receptor gene affects promoter activity. Biol psychiatry. 2004 Sep 15;56(6):406-10.

43. Smith RM, Papp AC, Webb A., et al. Multiple regulatory variants modulate expression of 5-hydroxytryptamine $2 \mathrm{~A}$ receptors in human cortex. Biol psychiatry. 2013 Mar 15;73(6):546-54.

44. Perlis RH, Patrick A, Smoller JW, et al. When is pharmacogenetic testing for antidepressant response ready for the clinic? A cost-effectiveness analysis based on data from the STAR* D study. Neuropsychopharmacology. 2009 Sep;34(10):2227.

45. Laje G, Cannon DM, Allen AS, et al. Genetic variation in HTR2A influences serotonin transporter binding potential as measured using PET and [11C] DASB. Int J Neuropsychopharmacol. 2010 Jul 1;13(6):715-24 